\title{
Teamwork and E-learning as a New Approach in High Education
}

\author{
Danijela Kardaš \\ University of Banja Luka, Bosnia and Herzegovina \\ Bojan Knežević \\ University of Banja Luka, Bosnia and Herzegovina \\ Petar Gvero \\ University of Banja Luka, Bosnia and Herzegovina
}

\begin{abstract}
Team work has become a central issue for many corporations, and self-managing teams are often viewed as the goal of team work development programs. The increased pressure on professionals to perform their tasks with fewer employees, at faster speeds, and with more quality and customer responsiveness creates the need for team work. In modern society and working place, dispersed teams are increasingly common in both large and small organizations. There are wide varieties of communication and collaboration options available. One of these is also using multifunctional rooms (MFR). This paper analyses introducing of a course "Team Project" on the first and second cycle of studies at University in Banja Luka, Faculty of Mechanical Engineering and using MFR as a tool in learning process. Introduction of this course and establishment of MFR came as a transfer of the knowledge, experience and technology from NTNU (Norwegian University of Science and Technology) to the Faculty of Mechanical Engineering within the project HERD QIMSEE (HERD Quality Improvement of Master Programs in Sustainable Energy and Environment). "Team Project" is experience - based learning course where students learn how to be a part of a team and work on multidisciplinary problems. MFR is used as a tool in this process.
\end{abstract}

Keywords: teamwork, skills, multidisciplinary, education, multifunctional room JEL classification: 123

\section{Introduction}

According to the "NMC Horizon Report" (NMC 2015), higher education continues to move away from traditional lecture-based programs to more hands-on scenarios, where University classrooms will start to resemble real-world work and social environments that facilitate organic interactions and cross-disciplinary problem solving. On the other hand, we can correlate these classrooms to the workplace of the future, where technology, people and processes interact and create a collaborative, contextual and visual environment, independent of physical location. Modern labour market and modern society need people who are capable to work together solving multidisciplinary problems with or without technology. Team work has become a central issue for many corporations, and self-managing teams are often viewed as the goal of team work development programs. The increased pressure on professionals to perform their tasks with fewer employees, at faster speeds, and with more quality and customer responsiveness creates the need for team work. This is especially apparent in research and development organizations 
where the complexity of the new projects and products and reduced life cycle of new products makes team work as a necessity. Research and development teams are both, the creators of new technology and the users of a variety of technological systems, especially communications technology. These technically oriented professionals need to work in a supportive organizational context in order to be successful.

Team-based learning (TBL) was firstly introduced in the literature in 1982. as a way to promote the benefits of small-group teaching in a large group setting, considerably enhancing students' engagement and their knowledge retention (Michaelsen, Watson, Cragin, Fink, 1982). In the 1990s, the focus of team work activities is changing. On the factory floor, companies which have been successful developing teams are continuing their organizational change efforts by trying to make the teams more self-managing (Manz, et.al 1992). Concurrent engineering requires increased team work among technical professionals and managers. The European Commission's "Modernizing Universities" agenda (CR, 2007) emphasize focusing on implementing reform in higher education by restructuring institutions to enable faculty and students to be active participants in the global marketplace of research and innovation. The EC's goals include stimulating a more open research environment, fostering stronger partnerships with businesses, and rethinking how qualifications are recognized. Therefore, new approaches in learning through technology and without it are more than welcome. This paper analyse introduction of new course "Team project" at Faculty of Mechanical Engineering and e-learning through this course using multifunctional rooms (MFR).

\section{HERD QIMSEE project at Faculty of Mechanical Engineering Banja LUka}

The Norwegian Ministry of Foreign Affairs is financing a program in Higher Education, Research and Development in the Western Balkans 2010-2016 (HERD). A sub program within HERD focuses on the energy sector. This paper refers to a project within the energy sector called: Quality Improvements of Master Programs in Sustainable Energy and Environment (QIMSEE). The projects members in QIMSEE are eight universities (Trondheim, Belgrade, East Sarajevo, Tuzla, Sarajevo, Banja Luka, Podgorica and Skopje). The main goal of the project is to improve the quality of education at Master's programs. A milestone in this project process is to enhance interconnections between universities, industry and the public. The project has a set of specific objectives: (i) Develop and establish three new internationally recognized master study programs for the field of "Sustainable Energy and Environment", at University of Banja Luka, University of Skopje and University of Montenegro, (ii) Increase the quality of the newly established master programs at the other four WB Universities in order to enable international transparency, recognition of qualifications and international mobility of learners and graduates. The tree new network members will also participate in all quality improvement processes, (iii) Establish close cooperation between WB participants for mutual support in achieving better quality of master studies, 8iv) Contribute to the development of outstanding and innovative master thesis projects that solves problems of industry and public sector in achieving energy and resource efficiency and/or zero emissions, application or research on new materials and new technologies for renewable energy, (v) Increase institutional quality and capacity of the WB Universities in the field of teaching staff improvement, laboratory organization and logistics, networking and supplementing expertise to match closer to the Norwegian partners, (vi) Establish and support interconnection of the WB Universities with industry and public 
sector in the WB region. To obtain some of the goals in the QIMSEE project listed above, Multifunctional Room (MFR) was established and new course "Team project" was introduced at Faculty of Mechanical Engineering Banja Luka.

\section{Methodology}

Today's global environment is allowing universities to unite across international borders and work toward common goals concerning technology, research, or shared values. Support behind technology-enabled learning and integration of sophisticated multimedia and communication technologies in higher education classrooms, gives us a lot of flexibility, which facilitates and increase the use of blended learning and flipped classrooms. More universities are helping to facilitate these emerging models of education, by rearranging learning environments to accommodate active learning. In the NMC Horizon Project (NMC, 2015), educational technology is defined in a broad sense as tools and resources that are used to improve teaching, learning and creative inquiry. According to the "NMC Horizon Report" (NMC 2015), higher education continues to move away from traditional lecture-based programs to more hands-on scenarios, where University classrooms will start to resemble real-world work and social environments that facilitate organic interactions and cross-disciplinary problem solving. On the other hand, we can correlate these classrooms to the workplace of the future, where technology, people and processes interact and create a collaborative, contextual and visual environment, independent of physical location. The European Commission's "Modernizing Universities" agenda ((CR, 2007) emphasize similar objectives as the QIMSEE project, focusing on implementing reform in higher education by restructuring institutions to enable faculty and students to be active participants in the global marketplace of research and innovation. This active learning can be supported with "Multifunctional Room - MFR". The major components in the design of MFR are space, technology and pedagogy (Radcliffe, 2015). In addition we add the users, which we can define as teachers/facilitators and learners within the QIMSEE project, and as collaborative and interacting users from the industry and private sector.

Figure 1

Pedagogy-Space-Technology Framework

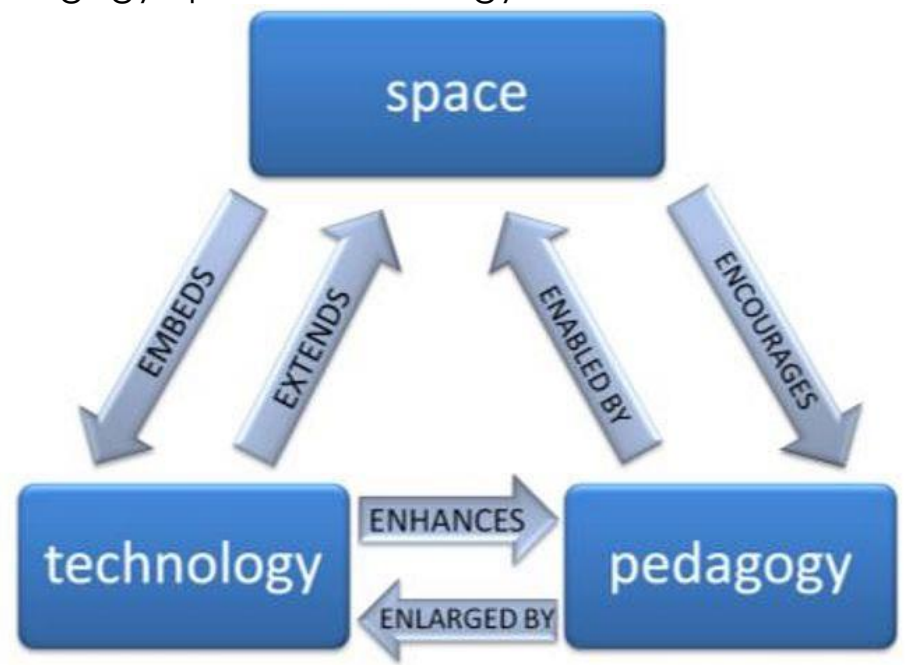

Source: Radcliff (2015) 
Multifunctional room (MFR) is optimized to facilitate videoconference and other types of $\mathrm{AV}$-communication, by improving acoustics (sound quality), lights for different videoconference settings and finally by using nice colours and materials to create a good atmosphere. Flexibility was paramount in the room design.

The traditional approach of teaching engineering subjects is efficient in presenting a large amount of information to large numbers of students. However, the downside of this approach is that it fosters passive learning where students expect to be told what to learn and how to learn it (Felder 2012), without developing the skills and enthusiasm for the course. Development of strong teamwork capabilities are highly required by employers in engineering sectors since engineering graduates are increasingly expected to work in team-based product and process design projects (Natishan, Schmidt, Mead 2000). Thus, team-based learning, if used effectively, helps improve communication, discussion, problem-solving, decision-making and creativity skills, as well as increasing the ability to work with others, an essential part of being in a social community (Türel, 2016). Faculty of Mechanical Engineering established the course "Team Project" and this came as a transfer of the knowledge and experience from Norwegian University of Science and Technology (NTNU) through HERD QIMSEE project. Course "Team Project" is similar to the course "Experts in Teamwork - EiT" which was established in 2001. at Norwegian University of Science and Technology in response to demands from business, industry and generally working life. Every year more than 2000 students attend EiT at NTNU. It's obligatory at second cycles of studies for all faculties. It takes 7 ECTS points as any other subject. EiT is organized in "villages" (village = class) of up to 30 students and each "village" is divided in groups of approximately 5 students. Students choose in which village they want to go depending on topic of the village. Due to that, villages have students from different field of studies working together on the same project. Through the interdisciplinary project the students gain skills that enable them to work together with people from different professional backgrounds and to ensure that they can function as a team. This is the way EiT prepare students for working life. Early research examining the differences between face-to-face and technology-mediated groups demonstrated some of the potential advantages of utilizing technology as a medium for accomplishing work in teams. It would be difficult to imagine, in today's workplace environment complete absence of mediating communication technologies (e.g., email, video-conferencing, shared calendars, etc.). Almost all teams are likely to employ at least some type of technology to coordinate tasks and accomplish work. Within the literature on virtual teams, the previously widespread view that teams are either virtual or not is increasingly challenged as being "unrealistic and artificial" (Kirkman \& Mathieu, 2005, p. 701; see also Cramton, 2001; Griffith, Sawyer, \& Neale, 2003; Martins et al., 2004). This perspective acknowledges that geographic dispersion may lead to team members using virtual means of coordinating task activities, however this does not preclude teams that are colocated from using virtual tools as well (Kirkman \& Mathieu, 2005). As "Team project" is experienced based learning, idea is to connect this type of learning with elearning. There are many definitions for e-learning from Educational dictionary: "ELearning identifies various types of computer-aided learning, usually using modern technology. E-learning is expanding especially in the sphere of distance education and corporate training" (Prucha, 2003), or a later definition: "E-learning can be understood as an educational process, using information and communication technologies to create training, to distribute learning content, communication between students and teachers and for management of studies" (Wagner, 2005). 


\section{Results}

Introduction of a course "Team project" at Faculty of Mechanical Engineering was also one of HERD QIMSEE project components. As mentioned before, course came as a transfer of the knowledge and experience from NTNU. This course has the same concept as "Experts in Teamwork" at NTNU. This course is established at first cycle of studies at Faculty of Mechanical Engineering and at second cycle of combined study program "Energy efficiency in Buildings". This is combined study program between Faculty of Mechanical Engineering and Faculty of Architecture and Civil Engineering. Due to that, students from both faculties can apply on this study program. At the University level doesn't exist any concept similar to the "Team Project".

At this phase, through QIMSEE project four MFR were equipped (Faculty of Mechanical Engineering Banja Luka, Faculty of Mechanical Engineering Sarajevo, Faculty of Mechanical Engineering East Sarajevo and Faculty of Mechanical Engineering Belgrade). Idea is to use these rooms and try to establish virtual student teams from these four faculties and put them to work together on the same project. As a part of the QIMSEE goals, we defined strategies to find ways of using low cost, flexible technology to enhance our learning and to enable technologies in new meaningful ways. MFR room is equipped with technology which can be very helpful for e-learning and team work:

- Interactive projector: The last years the interactive whiteboard has entered the classroom, and it has helped the teacher to create and present material in a more interactive and engaging way. A vast collection of new tools can improve teacher presentations and distribution of teaching material. Our choice of interactive projectors supports wireless connection of any mobile device (BYOD), connection of up to 8 projectors to one common workspace. Each node in the network can in real time, write and work on the same document displayed at the interactive projector. There are many more features, which enables real time networked communication and collaboration, between the nodes in the network.

- Document camera: The document camera will act as tool to import video/photo/recordings into the interactive projector for further processing. It provides many new opportunities to "import" material into the learning environment. Secondly, the document camera can support recordings of small videos with audio. These videos can be teacher examples or student presentations.

- Camera and videoconference: Two types of qualities/systems for the multifunctional rooms are used. Systems for small group or 1-1 communication are based on web cam solutions. On the other hand, professional Tandberg videoconference systems with a centrally located Multi Conferencing Unit (MCU) gives the option of sending a lecture from the one location to seven other locations in the QIMSEE network at the same time, with the option of twoway communication.

- BYOD: The MFR makes it possible to connect the students with learning opportunities using their own devices. Implemented solutions support different standards of sharing/mirroring displays. Students can do their own recordings of lab measurements, presentations of results etc. Students can be activated and interact with the teacher through student response systems. Communication through social media and other related audio-visual apps has become a natural part of every student's life, and it is up to the students and teachers to use this in a positive way, and integrate it as a part of the learning process. 


\section{Discussion}

Course "Team Project" brought one totally different approach to teaching methods and models which will enable professors and teaching assistants growth on professional level. Through the course we will try to connect this type of learning with e-learning. At this way, students will gain experience working in a team and also how to use technology on right way to accomplish project goals. As students will be at four different geographical locations and work together on same project, they will have to use technology to communicate and to work. Success of their project will depend on their ability to adjust on a new virtual working environment.

MFR have equipment mentioned above which teams can and have to use to achieve their project goals. We need to create a common understanding about what these rooms represent and how they can support the quality enhancement process of the education. This anchoring of understanding should be done on all levels in the University, from administration/technical staff to teachers and finally to the students.

It is of great importance that the room and its functions integrate with the development of new curriculum and the pedagogical methods used in presenting and learning the updated material. The technology in the MFR has no value without content and usage. The major challenge is to integrate the MFR into the education, and to motivate, inspire and train the technical staff, teachers and students in using the MFR, with all its features. These are some of the reasons why we want to start using MFR on the course "Team Project".

Other reasons are that this way of studding will prepare students for modern labour market and it will improve their professional competence.

\section{Conclusion}

This paper presents new, modern approach of education which is created as answer on demands from nowadays society and economy. Teamwork, knowledge, visionary, flexibility and leadership are desirable qualities of the modern academic employees. So, new course which is presented in the paper is implemented at Faculty of Mechanical Engineering and whose results encouraging. It is not possible to predict which results will produce the combination of the teamwork based education and technology available in multifunctional rooms. But, we have to and we will create opportunities to enlarge knowledge and competitions of the future holders of economic development.

\section{References}

1. CR (2007), "Council Resolution of 23 November 2007 on modernizing universities for Europe's competitiveness in a global knowledge economy", General Secretariat; No. prev.doc.15007/07 RECH 358 EDUC 212 COMPET 378; Brussels, 6 December 2007, 16096/1/07; REV 1.

2. Cramton, C. D. (2001), "The mutual knowledge problem and its consequences for dispersed collaboration", Organization Science, Vol. 12, pp 346-371.

3. Felder, R.M. (2012), Engineering education: a tale of two paradigms, In: McCabe, Bryan, Pantazidou, Marina, Phillips,Declan (Eds.), Shaking the Foundations of GeoEngineering Education, CRC Press, pp 9-14.

4. Griffith, T. L., Sawyer, J. E., Neale, M. A. (2003), "Virtualness and knowledge in teams: Managing the love triangle of organizations, individuals, and information technology", MIS Quarterly, Vol. 27, 265-287.

5. Kirkman, B. L., Mathieu, J. E. (2005), "The dimensions and antecedents of team virtuality", Journal of Management, Vol. 31, pp 700-718. 
6. Martins, L. L., Gilson, L. L., Maynard, M. T. (2004), "Virtual teams: What do we know and where do we go from here?", Journal of Management, Vol. 30, pp 805-835.

7. Michaelsen, L.K., Watson, W.E., Cragin, J.P., Fink, L.D. (1982), "Team-based learning: a potential solution to the problems oflarge classes", Exchange, Vol. 7, pp 18-33.

8. Manz, C. (1992), "Self-leading work teams: Moving beyond self-management myths", Human Relations, Vol. 45 No. 11 , pp. 1119.

9. NMC (2015), "NMZ Horizon Report: 2015", Higher Education Edition, ISBN 978-09906415-82.

10. Natishan, M.E., Schmidt, L.C., Mead, P. (2000), "Student focus group results on student team performance issues", J. Eng. Educ, Vol. 89, pp 269-272.

11. Prưcha, J., Walterová, E., Mareš, J. (2003), Pedagogický slovník, Praha, Portál, 4. Upravené vydání, ISBN 80-7367-416-5

12. Radcliffe, D. (2015), "A Pedagogy-Space Technology (PST) Framework for Designing and Evaluating Learning Places", available at: http://www.uq.edu.au/nextgenerationlearningspace/Chapterl.pdf (20 April 2017).

13. Wagner, J. (2005), Nebojme se elearningu, Česká škola.

14. Türel, Y. K. (2016), "Relationships between students' perceived team learning experiences, team performances, and social abilities in a blended course setting", Internet and Higher Education, Vol. 31, pp. 79-86.

\section{About the authors}

Danijela Kardaš MSc, is Assistant at the Faculty of Mechanical Engineering, University of Banja Luka, Thermal Department. Currently, she is working also for United Nations development Programm as Project Assistant at Green Economic Development Project. Her main research interests are renewable energy, energy efficiency, teamwork and e-learning. Through the HERD QIMSEE Project she was at Norwegian University of Science and Technology (NTNU) in Trondheim where she was working at intensive course "Experts in Teamwork". Danijela Kardaš participated in many scientific international and national conferences. Author can be contacted at danijela.kardas@mf.unibl.org.

Bojan Knežević, MSc. is an Assistant at the Faculty of Mechanical Engineering, University of Banja Luka, Department of Mechatronics. Currently, he is working on his PhD thesis at Faculty of Technical Science in Novi Sad. Through the exchange program for university studies he was at universities in Austria, Poland, Slovakia, Rumania, Bulgaria, Serbia and Croatia. His main research interests are mechatronic systems, energy efficiency, e-learning and mathematical modelling. Bojan Knežević published several scientific papers in international and national journals and participated in many scientific international conferences. Author can be contacted at bojan.knezevic@mf.unibl.org.

Petar Gvero, PhD, Full Professor on Faculty of Mechanical Engineering in Banja Luka born in January 30, 1966. Teaching subjects related to thermodynamics, combustion, thermal enquiring. He obtained his PhD diploma in 2003 in combustion science at University of Belgrade. He published 65 scientific and specialist papers in the journals and at the conferences and being involved in many projects from his fields. He is a member of different associations and bodies as FP7 H2O2O - Energy Program Committee on behalf of Bosnia and Herzegovina, Adria Section of Combustion Science Institute, and editorial board of the International journal Thermal Science. Author can be contacted at petar.gvero@mf.unibl.org. 